Table 1. History of advanced therapy on or within 12 months pre-index in pts with PsA

\begin{tabular}{lcc}
\hline & $\begin{array}{c}\text { All pts } \\
\mathbf{( N = 4 4 0 )}\end{array}$ & $\begin{array}{c}\text { Pts with no RA } \\
(\mathbf{N}=\mathbf{3 1 5})\end{array}$ \\
\hline $\begin{array}{l}\text { Pts exposed to advanced therapy, } \mathrm{n}(\%)^{\mathrm{b}} \\
\text { Any advanced therapy }\end{array}$ & & \\
Secukinumab & $336(76.4)$ & $241(76.5)$ \\
Adalimumab & $113(25.7)$ & $91(28.9)$ \\
Apremilast & $93(21.1)$ & $58(18.4)$ \\
Etanercept & $81(18.4)$ & $59(18.7)$ \\
Unique advanced therapy prescriptions & $70(15.9)$ & $47(14.9)$ \\
Mean (SD) & & \\
Median (IQR) & $1.1(0.8)$ & $1.1(0.8)$ \\
Range & $1(1-2)$ & $1(1-2)$ \\
Number of unique advanced therapies, $\mathrm{n}(\%)$ & $0-4$ & $0-4$ \\
0 & & $74(23.5)$ \\
1 & $104(23.6)$ & $153(48.6)$ \\
2 & $214(48.6)$ & $73(23.2)$ \\
$\geq 3$ & $100(22.7)$ & $15(4.8)$ \\
\hline
\end{tabular}

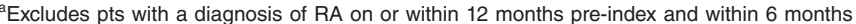
post-index; ${ }^{\mathrm{b}} \mathrm{Pts}$ with $\geq 1$ claim for biologic DMARDs or apremilast within 12 months pre-index; 'Other advanced therapies reported in $<10 \%$ of all pts were abatacept, certolizumab, golimumab, infliximab, ixekizumab and ustekinumabIQR, interquartile range; $\mathrm{N}$, number of pts per cohort; $\mathrm{n}$, number of pts per category; SD, standard deviation

Figure. Tofacitinib treatment a) persistences and b) adherence $(P D C \geq 0.8)^{b}$ in pts with PSA at 6 months post-index
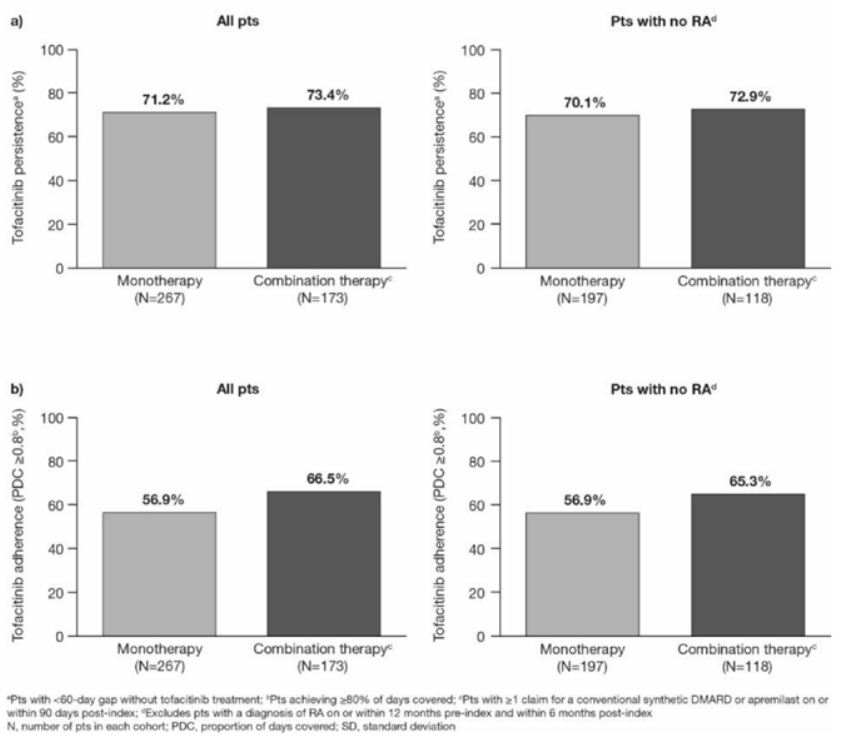

Figure 1

Conclusion: This analysis of US-based claims data indicated that pts newly initiated tofacitinib treatment an average of 2 years after PsA diagnosis, with the majority $(>60 \%)$ of pts receiving tofacitinib as monotherapy. High levels of persistence and adherence to tofacitinib were observed 6 months after treatment initiation. Findings were similar when pts with PsA who also had a diagnosis of RA were excluded. Data were limited in that claims data cannot confirm that pts took the medication for which they filed a claim.

Acknowledgements: Study sponsored by Pfizer Inc. Medical writing support was provided by Gemma Turner, CMC Connect, and funded by Pfizer Inc.

Disclosure of Interests: Philip J Mease Speakers bureau: AbbVie, Amgen, Bristol-Myers Squibb, Celgene, Eli Lilly, Genentech, Janssen, Novartis, Pfizer Inc, UCB, Consultant of: AbbVie, Amgen, Boehringer Ingelheim, Bristol-Myers Squibb, Celgene, Eli Lilly, Galapagos, Gilead, Janssen, Novartis, Pfizer Inc, Sun, UCB, Grant/research support from: AbbVie, Amgen, Boehringer Ingelheim, Bristol-Myers Squibb, Celgene, Eli Lilly, Galapagos, Gilead, Janssen, Novartis, Pfizer Inc, Sun, UCB, Pamela Young Shareholder of: Pfizer Inc, Employee of: Pfizer Inc, David C Gruben Shareholder of: Pfizer Inc, Employee of: Pfizer Inc, Lara Fallon Shareholder of: Pfizer Inc, Employee of: Pfizer Inc, Rebecca Germino Shareholder of: Pfizer Inc, Employee of: Pfizer Inc, Arthur Kavanaugh Grant/research support from: Pfizer Inc. DOI: 10.1136/annrheumdis-2021-eular.390

\section{AB0522 1 SAFETY PROFILE OF UPADACITINIB UP TO 3 YEARS IN PATIENTS WITH PSORIATIC ARTHRITIS: AN INTEGRATED ANALYSIS FROM THE PHASE 3 PROGRAM}

G. R. Burmester ${ }^{1}$, K. Winthrop ${ }^{2}$, R. Blanco ${ }^{3}$, P. Nash ${ }^{4}$, P. Goupille ${ }^{5}$, V. F. Azevedo ${ }^{6}$, C. Salvarani ${ }^{7}$, A. Rubbert-Roth ${ }^{8}$, E. Lesser ${ }^{9}$, R. Mccaskill ${ }^{9}$, J. Liu $^{9}$, B. Pierre-Louis ${ }^{9}$, S. Walko ${ }^{9}$, R. Lippe ${ }^{10}$, A. Lertratanakul ${ }^{9}$, E. Ruderman ${ }^{11}$. ${ }^{1}$ Charité University Medicine, Rheumatology and Clinical Immunology, Berlin, Germany; ${ }^{2}$ Oregon Health and Science University, School of Medicine, Oregon, United States of America; ${ }^{3}$ Hospital University Marques de Valdecilla, Division of Rheumatology, Santander, Spain; ${ }^{4}$ Griffith University, School of Medicine, Brisbane, Australia; ${ }^{5}$ University Hospital and CIC1415, Department of Rheumatology, Tours, France; ${ }^{6}$ Federal University of Paraná, Department of Internal Medicine, Curitiba, Brazil; ${ }^{7}$ Azienda USL-IRCCS di Reggio Emilia and Università di Modena e Reggio Emilia, Rheumatology Unit, Reggio Emilia, Italy; ${ }^{8}$ Cantonal Clinic St Gallen, Division of Rheumatology, St Gallen, Switzerland; ${ }^{9} \mathrm{Abb} V i e$, Immunology, North Chicago, United States of America; ${ }^{10} \mathrm{AbbVie}$ Deutschland GmbH \& Co. KG, Immunology, Wiesbaden, Germany; ${ }^{11}$ Northwestern University, Feinberg School of Medicine, Chicago, United States of America

Background: The efficacy and safety of upadacitinib (UPA), an oral Janus kinase inhibitor, in patients (pts) with active psoriatic arthritis (PsA) were demonstrated through 24 weeks in the phase 3 SELECT-PSA 1 and SELECT-PSA 2 placebo-controlled clinical trials. ${ }^{1,2}$

Objectives: To describe the long-term integrated safety profile of UPA relative to adalimumab (ADA) in pts with PsA treated in the SELECT program.

Methods: The SELECT-PsA program enrolled pts with prior inadequate response or intolerance to $\geq 1$ non-biologic DMARD (SELECT-PSA 1 ) or $\geq 1$ biologic DMARD (SELECT-PsA 2). Both trials include UPA $15 \mathrm{mg}$ and $30 \mathrm{mg}$, and only SELECT-PSA 1 includes long-term comparison with ADA $40 \mathrm{mg}$ every other week. Treatment-emergent adverse events (TEAEs: $A E$ onset $\geq$ first dose and $\leq 30$ days after last dose for UPA and $\leq 70$ days for ADA) were summarized for the following: pooled UPA 15; pooled UPA 30; and ADA. TEAEs are reported as exposure-adjusted event rates (EAERs; events/100 pts years [E/100 PY]) up to a cut-off date of 20 June 2020

Results: 2257 pts received $\geq 1$ dose of UPA 15 ( $N=907 ; 1247.2$ PYs), UPA 30 ( $\mathrm{N}=921 ; 1257.4 \mathrm{PYs})$, or ADA ( $\mathrm{N}=429$; $549.7 \mathrm{PYs})$, with median (max) exposures of 69 (155), 69 (154), and 68 (152) weeks, respectively. EAERs of TEAEs and serious AEs were generally similar between UPA 15 and ADA and higher with UPA 30; rates of AEs leading to study drug discontinuation were generally similar across all groups (Table 1). Similarly, rates of serious infection were comparable between UPA 15 and ADA and higher with UPA 30 (Figure 1 next page). The most common serious infection was pneumonia. Rates of herpes zoster were lower with UPA 15 than UPA 30 but higher than ADA. Most herpes zoster events involved a single dermatome; no events involved the central nervous system or other internal organs. Lower rates of opportunistic infections $(\mathrm{OI})$ excluding tuberculosis were observed with UPA 15 vs UPA 30 ; the most common OI was mucosal candida infection. Malignancies were reported at similar rates across all treatment groups; no events of lymphoma were reported. Age-gender-adjusted standardized incidence ratios for malignancies excluding NMSC indicated no increased risk with UPA compared to the general population. Rates of adjudicated major adverse cardiovascular events and venous thromboembolic events were $\leq 0.3 \mathrm{E} / 100 \mathrm{PY}$ for both UPA arms; all pts had $\geq 1$ risk factor. One adjudicated gastrointestinal perforation was reported with UPA 15

Table 1. Overall Treatment-emergent AEs for Upadacitinib and Adalimumab (E/100 PY [95\% CI])

\begin{tabular}{|c|c|c|c|}
\hline & $\begin{array}{c}\text { UPA } 15 \mathrm{mg} \text { QD } \\
\text { N=907 } \\
(1247.2 \mathrm{PY})\end{array}$ & $\begin{array}{c}\text { UPA } 30 \mathrm{mg} \text { QD } \\
\mathrm{N}=921 \\
(1257.4 \mathrm{PY})\end{array}$ & $\begin{array}{c}\text { ADA } 40 \mathrm{mg} \text { EOW } \\
\mathrm{N}=429 \\
(549.7 \mathrm{PY})\end{array}$ \\
\hline AEs & $263.9(254.9,272.9)$ & $321.5(311.6,331.5)$ & $\begin{array}{c}286.5(272.4, \\
300.7)\end{array}$ \\
\hline Serious AEs & $10.3(8.6,12.1)$ & $13.2(11.2,15.2)$ & $9.6(7.0,12.2)$ \\
\hline $\begin{array}{l}\text { AE leading to } \\
\text { discontinuation }\end{array}$ & $6.7(5.2,8.1)$ & $7.8(6.2,9.3)$ & $7.8(5.5,10.2)$ \\
\hline Death $^{\mathrm{a}}$ & $0.2(-0.1,0.4)$ & $0.2(-0.0,0.5)$ & $0.2(-0.2,0.5)$ \\
\hline
\end{tabular}

${ }^{a}$ Deaths included non-treatment emergent deaths: UPA 15, 1; UPA 30, 1.ADA, adalimumab; $\mathrm{AE}$, adverse event; $\mathrm{Cl}$, confidence interval; $\mathrm{E}$, event; EOW, every other week; PY, patient years; $\mathrm{QD}$, once daily; UPA, upadacitinib. 
Hepatic disorders were mostly transient, non-serious transaminase increases Creatine phosphokinase elevations were reported more frequently with UPA 30 vs UPA 15; most were asymptomatic with no rhabdomyolysis reported. AEs of anemia, neutropenia, and lymphopenia were generally mild or moderate, non-serious. Except for rates of lymphopenia (higher with UPA 15), hepatic disorders, and neutropenia (both higher with ADA), lab-related TEAEs occurred at generally consistent rates between UPA 15 and ADA. Study drug discontinuation due to lab-related TEAEs was uncommon.

Conclusion: The safety profiles of UPA 15 and ADA were generally similar; the rates of most AEs were higher with UPA 30 compared with ADA. Through the cut-off date, the safety profile of UPA 15 and UPA 30 in PsA pts demonstrated consistent results compared to what has been observed with UPA in rheumatoid arthritis. $^{3}$

\section{REFERENCES}

[1] Mclnnes IB et al. Ann Rheum Dis, 2020; 79:12.

[2] Mease PJ et al. Ann Rheum Dis, 2020.

[3] Cohen SB et al. Ann Rheum Dis, 2020.

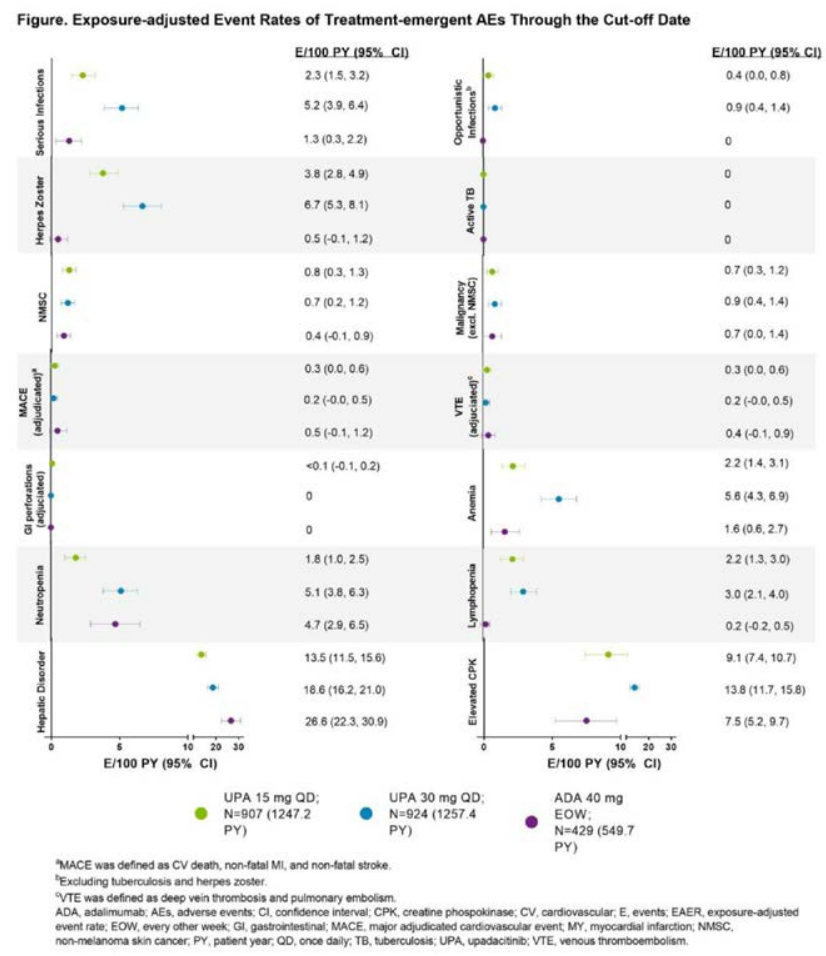

Figure 1

Acknowledgements: AbbVie and the authors thank the patients, study sites, and investigators who participated in this clinical trial. AbbVie, Inc was the study sponsor, contributed to study design, data collection, analysis \& interpretation, and to writing, reviewing, and approval of final version. No honoraria or payments were made for authorship. Medical writing support was provided by Ramona Vladea, PhD of AbbVie Inc.

Disclosure of Interests: Gerd Rüdiger Burmester Speakers bureau: AbbVie Gilead, Lilly, Pfizer, Consultant of: AbbVie, Gilead, Lilly, Pfizer, Kevin Winthrop Consultant of: UCB Pharma, Pfizer, Bristol-Myers Squibb, Eli Lilly, AbbVie Gilead, Galapagos, and Roche, Grant/research support from: UCB Pharma Pfizer, Bristol-Myers Squibb, Eli Lilly, AbbVie, Gilead, Galapagos, and Roche, Ricardo Blanco Consultant of: Abbvie, Lilly, Novartis, Pfizer, Roche, Bristol-Myers, Janssen, and MSD, Grant/research support from: Abbvie, MSD and Roche, Peter Nash Consultant of: AbbVie, BMS, Roche, Pfizer, Janssen, Amgen, Sanofi-Aventis, UCB, Eli Lilly, Novartis, and Celgene, Grant/research support from: AbbVie, BMS, Roche, Pfizer, Janssen, Amgen, Sanofi-Aventis, UCB, Eli Lilly, Novartis, and Celgene, Philippe Goupille Consultant of: AbbVie, Amgen, Biogen, BMS, Celgene, Chugai, Janssen, Lilly, Medac, MSD, Nordic Pharma, Novartis, Pfizer, Sanofi and UCB, Grant/research support from: AbbVie, Amgen, Biogen, BMS, Celgene, Chugai, Janssen, Lilly, Medac, MSD, Nordic Pharma Novartis, Pfizer, Sanofi and UCB, Valderilio F Azevedo Consultant of: AbbVie BMS, Pfizer, Janssen, Amgen, Novartis, Eli Lilly, UCB, Celltrion and GSK, Grant research support from: AbbVie, BMS, Pfizer, Janssen, Amgen, Novartis, Eli Lilly, UCB, Celltrion and GSK, Carlo Salvarani Consultant of: Roche, Sanofi-Genzyme, AbbVie, Pfizer, Lilly, Novartis, Amgen, Grant/research support from: Roche, Sanofi-Genzyme, AbbVie, Pfizer, Lilly, Novartis, Amgen, Andrea Rubbert-Roth Consultant of: AbbVie, BMS, Chugai, Roche, Gilead, Janssen, Lilly,
Sanofi, Amgen, Novartis, Grant/research support from: AbbVie, BMS, Chugai, Roche, Gilead, Janssen, Lilly, Sanofi, Amgen, Novartis, Elizabeth Lesser Shareholder of: AbbVie, Employee of: AbbVie, Reva McCaskill Shareholder of: AbbVie, Employee of: AbbVie, Jianzhong Liu Shareholder of: AbbVie, Employee of: AbbVie, Bosny Pierre-Louis Shareholder of: AbbVie, Employee of: AbbVie, Sandra Walko Shareholder of: AbbVie, Employee of: AbbVie, Ralph Lippe Shareholder of: AbbVie, Employee of: AbbVie, Apinya Lertratanakul Shareholder of: AbbVie, Employee of: AbbVie, Eric Ruderman Consultant of: AbbVie, Amgen, Gilead, Janssen, Lilly, Novartis, and Pfizer.

DOI: 10.1136/annrheumdis-2021-eular.395

\begin{tabular}{|l|l|}
\hline AB0523 & LONG-TERM SAFETY AND EFFECTIVENESS OF \\
& UPADACITINIB IN PATIENTS WITH PSORIATIC \\
& ARTHRITIS: RESULTS AT 56 WEEKS FROM THE \\
& SELECT-PSA 1 STUDY
\end{tabular}

$\underline{\text { I. Mclnnes }}^{1}$, K. Kato ${ }^{2}$, M. Magrey ${ }^{3}$, J. F. Merola ${ }^{4,5}$, M. Kishimoto ${ }^{6}$, C. F. Pacheco Tena $^{7}$, D. Haaland ${ }^{8,9}$, L. Chen ${ }^{2}$, Y. Duan ${ }^{2}$, P. Zueger ${ }^{2}$, J. Liư ${ }^{2}$, R. Lippe ${ }^{10}$, A. Pangan ${ }^{2}$, F. Behrens ${ }^{11}$. ${ }^{1}$ University of Glasgow, College of Medical Veterinary and Life Sciences, Glasgow, United Kingdom; ${ }^{2}$ AbbVie, Immunology, North Chicago, United States of America; ${ }^{3}$ MetroHealth Medical Center, Case Western Reserve University School of Medicine, Cleveland, United States of America; ${ }^{4}$ Harvard Medical School, Division of Rheumatology, Boston, United States of America; ${ }^{5}$ Brigham and Women's Hospital, Division of Rheumatology, Immunology and Allergy, Boston, United States of America; ${ }^{6}$ Kyorin University School of Medicine, Department of Nephrology and Rheumatology, Tokyo, Japan; ${ }^{7}$ Universidad Autonoma de Chihuahua, Facultad de Medicina, Chihuahua, Mexico; ${ }^{8}$ McMaster University, Hamilton, Canada; ${ }^{9}$ The Waterside Clinic, Barrie, Canada; ${ }^{10}$ AbbVie Deutschland GmbH \& Co. KG, Immunology, Wiesbaden, Germany; ${ }^{11}$ Goethe University \& Fraunhofer IME-TMP and CIMD, Frankfurt, Germany

Background: In the SELECT-PSA 1 study, through 24 weeks (wks), once daily upadacitinib $15 \mathrm{mg}$ (UPA15) and $30 \mathrm{mg}$ (UPA30) showed improvements in musculoskeletal symptoms, psoriasis, physical function, pain, fatigue, and quality of life, as well as inhibition of radiographic progression in patients (pts) with psoriatic arthritis (PsA) and inadequate response or intolerance to $\geq 1$ non-biologic disease-modifying antirheumatic drug (DMARD).

Objectives: To report the efficacy and safety of UPA vs adalimumab (ADA) up to 56 wks from the ongoing long-term extension of SELECT-PSA 1.

Methods: Pts received UPA15 or UPA30, ADA 40mg every other wk for 56 wks, or PBO through wk 24 switched thereafter to either UPA15 or UPA30 until wk 56. Efficacy endpoints as listed and defined in the Table 1 were analyzed at wk 56 Results for binary endpoints are based on non-responder imputation analysis treatments were compared using the Cochran-Mantel-Haenszel test. Results for non-radiographic continuous endpoints are based on mixed model repeated measures model based on as observed data. Radiographic endpoints were analyzed based on linear extrapolation. Treatment-emergent adverse events (TEAEs) per 100 pt years (PY) were summarized for pts who received $\geq 1$ dose of study drug.

Table 1. Efficacy Endpoints at Week 56

\begin{tabular}{|c|c|c|c|c|c|}
\hline Endpoint & $\begin{array}{l}\text { PBO } \rightarrow \\
\text { UPA15 }\end{array}$ & $\begin{array}{l}\text { PBO } \rightarrow \\
\text { UPA30 }\end{array}$ & UPA15 & UPA30 & ADA \\
\hline ACR20, \% & 73.0 & 74.1 & 74.4 & $74.7^{\#}$ & 68.5 \\
\hline ACR $50, \%$ & 54.5 & 60.4 & $59.7^{\star}$ & $60.5^{\#}$ & 51.3 \\
\hline ACR70, \% & 29.9 & 35.8 & $40.6^{\star}$ & $43.7^{\#}$ & 31.2 \\
\hline Minimal Disease Activity, \% & 29.4 & 35.8 & 44.8 & $47.3^{\#}$ & 39.6 \\
\hline $\mathrm{PASI} 5^{\mathrm{a}}, \%$ & 58.3 & 60.2 & 65.4 & 63.3 & 61.1 \\
\hline PASI90ª $\%$ & 41.7 & 53.7 & 49.1 & 49.5 & 46.9 \\
\hline PASI $100^{\mathrm{a}}, \%$ & 22.3 & 38.9 & 34.6 & 39.5 & 31.3 \\
\hline $\begin{array}{l}\text { Resolution of enthesitis by Leeds Enthesitis } \\
\text { Index }{ }^{\mathrm{b}}, \%\end{array}$ & 38.1 & 45.5 & 59.3 & 58.1 & 54.0 \\
\hline $\begin{array}{l}\text { Resolution of dactylitis by Leeds Dactylitis } \\
\text { Index }{ }^{c}, \%\end{array}$ & 47.7 & 59.0 & 75.0 & 74.8 & 74.0 \\
\hline $\begin{array}{l}\Delta \text { from BL in Bath Ankylosing Spondylitis } \\
\text { Disease Activity Index }{ }^{\text {d }}\end{array}$ & -3.1 & -3.1 & -3.3 & -3.2 & -2.8 \\
\hline $\begin{array}{l}\Delta \text { from BL in modified total Sharp/van der } \\
\text { Heijde Score (mTSS) }\end{array}$ & \multicolumn{2}{|c|}{$0.44^{\mathrm{e}}$} & $-0.05^{\dagger}$ & $0.02^{\ddagger}$ & -0.06 \\
\hline
\end{tabular}

* and $\uparrow, p \leq 0.05$; for UPA 15 vs ADA and PBO, respectively; \# and $\ddagger, p \leq 0.05$; for UPA30 vs ADA and $\mathrm{PBO}$, respectively. ${ }^{\mathrm{a}}$ for pts with psoriasis affecting $\geq 3 \%$ of body surface area at $\mathrm{BL} .{ }^{\mathrm{b}}$ for pts with $\mathrm{LEI}>0$ at BL. ${ }^{\mathrm{c}}$ for pts with $\mathrm{LDI}>0$ at $\mathrm{BL} .{ }^{\mathrm{d}}$ for pts with psoriatic spondylitis at BL. ${ }^{\mathrm{e}}$ pooled PBO.ACR20/50/70, $\geq 20 \% / 50 \% / 70 \%$ improvement in American College of Rheumatology criteria; ADA, adalimumab; BL, baseline; PASI75/90/100, $\geq 75 \% / 90 \% / 100 \%$ improvement in Psoriasis Area and Severity Index; PBO, placebo; pts, patients; UPA, upadacitinib.

Results: Of 1704 pts who received $\geq 1$ dose of study drug, 1419 (83.2\%) completed 56 wks of treatment on study drug. Across all treatment groups, the proportions of pts who had achieved ACR20/50/70, MDA, PASI75/90/100, resolution 